\title{
Penerapan Model POE2WE Berbasis Blog Wordpress sebagai Inovasi Pembelajaran Digital di Sekolah Menengah Atas
}

\author{
Muhammad Syarif Hidayat ${ }^{1^{*}}$, Nana ${ }^{2}$ \\ ${ }^{1}$ Mahasiswa Program Studi Pendidikan Fisika, Universitas Siliwangi \\ ${ }^{2}$ Dosen Program Studi Pendidikan Fisika, Universitas Siliwangi \\ *email korespondensi : syarifdasai07@gmail.com
}

\begin{abstract}
The purpose of writing this article is to describe the creative application of the wordpress blog-based POE2WE model as a learning innovation. This paper is motivated by the lack of understanding of students in mastering the material so that learning is not optimal. For this reason, there is a need for innovation in learning by applying the creative POE2WE model based on wordpress blogs. The POE2WE model as a solution process through a constructivist approach is accompanied by a wordpress blog so students become motivated and can improve their learning outcomes. The method used in this article is the study of literature or literature. Data from the literature is collected and analyzed to be presented in the results and discussion to draw conclusions. The results of the writing show that the creative application of the POE2WE model based on wordpress blogs as a learning innovation can be a solution to the problems encountered in the teaching and learning process in the classroom. The POE2WE model is applied to high school students in several stages, namely: students make a guess about the problem, after the problem is traced or observed, students explain lessons related to the problem and apply the concept of learning in the problem in daily life, then the students make written communication through wordpress blog, then do the evaluation and selection process to find solutions to problems that have been predicted and found. After that, students discuss with other groups through wordpress blogs that can be accessed and consulted by other groups during learning. Studying POE2WE creatively using a wordpress blog can allow maximum student participation in class. So, the need for students to be ready to accept various innovations.
\end{abstract}

Keywords: POE2WE, Learning Innovation, Wordpress blog

\begin{abstract}
ABSTRAK: Tujuan penulisan artikel ini adalah untuk menggambarkan aplikasi kreatif model POE2WE berbasis blog wordpress sebagai inovasi pembelajaran. Tulisan ini dilatarbelakangi oleh kurangnya pemahaman siswa dalam penguasaan materi sehingga pembelajaran tidak maksimal. Untuk alasan ini, ada kebutuhan untuk inovasi dalam belajar dengan menerapkan model POE2WE secara kreatif berbasis blog wordpress. Model POE2WE sebagai proses solusi melalui pendekatan konstruktivistik disertai dengan blog wordpress sehingga siswa menjadi termotivasi dan dapat meningkatkan hasil belajar mereka. Metode yang digunakan dalam artikel ini adalah studi literatur atau pustaka. Data dari literatur dikumpulkan dan dianalisis untuk disajikan dalam hasil dan diskusi untuk menarik kesimpulan. Hasil penulisan menunjukkan bahwa aplikasi kreatif model POE2WE berbasis blog wordpress sebagai inovasi pembelajaran dapat menjadi solusi untuk masalah yang dihadapi dalam proses belajar mengajar di kelas. Model POE2WE diterapkan untuk siswa sekolah menengah atas dalam beberapa tahap, yaitu: siswa membuat dugaan masalah, setelah masalah ditelusuri atau diamati, peserta didik menjelaskan pelajaran yang berkaitan dengan masalah itu dan menerapkan konsep pembelajaran dalam masalah tersebut di kehidupan sehari-hari, kemudian para siswa membuat komunikasi tertulis melalui blog wordpress, kemudian melakukan proses evaluasi dan seleksi untuk menemukan solusi atas masalah yang telah diprediksi dan ditemukan. Setelah itu, para siswa berdiskusi dengan yang kelompok lain melalui blog wordpress yang dapat diakses dan dikonsultasikan oleh kelompok lain selama pembelajaran. Mempelajari POE2WE secara kreatif menggunakan blog wordpress dapat memungkinkan partisipasi siswa secara maksimum di kelas. Maka, perlunya siswa untuk siap menerima berbagai inovasi.
\end{abstract}

Kata Kunci: POE2WE, Inovasi Pembelajaran, Wordpress blog 


\section{PENDAHULUAN}

Fisika adalah cabang ilmu pengetahuan alam (IPA) yang mempelajari fenomena alam yang tidak hidup atau materi di dalam lingkungan ruang dan waktu, serta semua interaksi yang menyertainya. Fisika adalah ilmu yang mempelajari tentang sebab dan akibat mengenai fenomenafenomena alam. Pembelajaran mengenai disiplin ilmu fisika sangatlah penting dipelajari (Nurhidayat et al., 2019). Perkembangan teknologi menjadi kemunculan berbagai teknologi baru di suatu negara. Tren ini terkait dengan alat yang memiliki kreativitas yang mampu mendesain materi dan mendesain pembelajaran menjadi lebih baik dan lebih presisi. Dalam praktiknya, pembelajaran di sekolah harus menghadirkan berbagai inovasi yang dapat meningkatkan daya kreatif siswa. Peserta didik tidak hanya dapat mendengar dan memahami dalam pembelajaran, tetapi juga bagaimana memiliki keterampilan dalam mengelola informasi yang diberikan oleh guru untuk dicerna dengan ide-ide kreatif. Untuk alasan ini, kebutuhan peserta didik untuk siap menggunakan berbagai teknologi dengan benar tidak membatasi alasan mereka untuk memperbarui pembelajaran mereka.

Dalam inovasi atau pembaharuan pembelajaran akan ada banyak hambatan untuk mengaktifkan kreativitas dan daya nalar peserta didik karena tingkat kepintaran peserta didik yang berbeda-beda. Pasti hal itu menjadi patokan atau tolak ukur dalam pembelajaran di kelas juga di luar kelas.

Penyampaian pembelajaran dengan menggunakan teknologi harus memperhatikan berbagai konten yang sesuai dengan batasan umurnya agar tidak terfokus dari inovasi yang digunakan. Namun dalam hal ini, tidak begitu mudah untuk menyebarkan berbagai teknologi yang inovatif di sekolah-sekolah dikarenakan berbagai paham dan sejarah sekolah yang berpengaruh pada pelaksanaannya (Nana, 2018: 191).

Perbedaan tersebut dapat dipengaruhi oleh motivasi yang ingin dicapai oleh guru, karakteristik siswa, cara penyampaian dalam memberi tugas belajar (Findikoglu dan Ilham, 2016: 2575-2576). Selain itu, pentingnya berinovasi dalam pembelajaran agar nantinya mampu bersaing di kancah internasional dengan memperhatikan berbagai kekuatan baik teknologi dari dalam maupun dari luar. Dalam situasi ini, tidak mudah untuk menganggap semuanya mudah karena butuh orang yang benar-benar kreatif (Seryukov, 2017: 5; Nana, 2018: 191).

Pengembangan inovasi pembelajaran dilakukan dengan cara mengadopsi model-model pembelajaran menyenangkan yang bisa membuat Peserta didik tidak jenuh selama pembelajaran berlangsung. Melalui model pembelajaran inovatif, peserta didik akan terbebas dari perasaan bosan, jenuh, khawatir akan kegagalan atau perasaan tertekan dalam melaksanakan berbagai tugas dan lainlain (Nurdyansyah dan Widodo, 2015: 28).

Pada hakikatnya, kegiatan berinovasi membutuhkan strategi dan keterampilan yang mampu meningkatkan efektivitas belajar siswa. Penggunaan model yang tepat dan sesuai dengan pencapaian yang ingin diperoleh oleh guru. Secara garis besar penggunaan model juga harus fleksibel karena didasarkan pada situasi dan kondisi di sekolah dengan tujuan untuk merangsang daya kreatif siswa (Yu Je Lee, 2011: 93). Di sisi lain, pengalaman yang diperoleh siswa selama pembelajaran di tingkat sebelumnya yang secara sadar maupun tidak sadar akan berpengaruh pada keberhasilannya dalam belajar serta meningkatkan motivasi. Cara untuk meningkatkan motivasi siswa dalam belajar yaitu dengan memberikan berbagai masalah-masalah yang berbeda-beda (Nana, 2018: 191).

Aplikasi teknologi informasi dan komunikasi yang merupakan pengembangan teknologi, diantaranya adalah media komputer. Komputer merupakan alat dan aplikasi teknologi berbasis informasi dan komunikasi yang dimanfaatkan sebagai perangkat utama untuk mengolah data menjadi informasi yang bermanfaat dengan memproses, menyajikan, dan mengelola informasi. Pengolahan data dengan komputer disebut dengan Pengolahan Data Elektronik (Electronic Data Processing - EDP)(Nana dan Surahman, 2019;2020). 
Masalah-masalah harus memenuhi kriteria yaitu mampu menciptakan kreatif siswa, dibuat untuk dipecahkan secara berkelompok, berkaitan dengan kekuatan diri sehingga siswa tidak hanya mampu mencerna permasalahan tetapi cara bersosialisasi dengan terlibat dalam diskusi (Valqui Vidal, 2010: 407-408). Masalah-masalah tersebut perlu diselesaikan dengan pembelajaran yang inovatif yaitu melalui model POE2WE. Model pembelajaran POE2WE dapat menjadikan peserta didik sebagai subjek di dalam pembelajaran. peserta didik secara aktif menemukan suatu konsep melalui pengamatan atau eksperimen secara langsung, bukan dari menghafal buku materi maupun penjelasan dari guru (Nana dan Surahman, 2019;2020)..

Pendekatan dalam model kreatif dalam memecahkan masalah adalah dengan melihat potensi masing-masing siswa yang dikaitkan dengan gaya belajar. Perbedaan gaya belajar berpengaruh pada perolehan pengetahuan yang didapat untuk dipahami dan dicerna (Basadur et al, 2014: 86). Penyesuaian gaya belajar dan pemahaman konsep menggunakan model POE2WE adalah hal yang penting melalui penyesuaian inovasi yang dikembangkan dengan pendekatan kontruktivistik. Keberhasilan dalam pencapaian model POE2WE dapat diiringi dengan penggunaan blog (blog engine). Blog sebagai sarana berkomunikasi secara maya. Artinya siswa dapat belajar dengan menggunakan blog sebagai pemacu daya kreatifnya (Boyd, 2006: 8).

Wordpress adalah sebuah aplikasi sumber terbuka (open source) yang sangat popular digunakan sebagai mesin blog (blog engine). Wordpress dibangunkan dengan bahasa pemrograman PHP dan basis data (Database). Wordpress juga mulai digunakan sebagai sebuah CMS (Conten Management System) karena kemampuannya untuk dimodifikasi dan disesuaikan dengan kebutuhan penggunanya (Sunarti dan Safitri, 2019: 47).

Berdasarkan Pemaparan diatas, maka perlunya membahas bagaimana cara menerapkan Model POE2WE Berbasis Wordpress sebagai Inovasi Pembelajaran Digital di Sekolah Menengah Atas.

\section{METODE PENELITIAN}

Metode yang digunakan dalam artikel ini adalah studi literatur atau pustaka. Data dikumpulkan dan dianalisis untuk disajikan dalam hasil dan pembahasan untuk menarik kesimpulan.

\section{HASIL DAN PEMBAHASAN}

\subsection{Model POE2WE}

Model pembelajaran Prediction, Observation, Explanation, Elaboration, Write dan Evaluation (POE2WE) dikembangkan dari model pembelajaran POEW dan model pembelajaran Fisika dengan Pendekatan Konstruktivistik. Pengembangan ini dilakukan untuk sebagai penyempurnaan kedua model sebelumnya. Model POE2WE merupakan model pembelajaran yang dikembangkan untuk mengetahui pemahaman peserta didik mengenai suatu konsep dengan pendekatan konstruktivistik. Model ini membangun pengetahuan dengan urutan proses yaitu meramalkan atau memprediksi solusi dari permasalahan, melakukan eksperimen untuk membuktikan prediksi, kemudian menjelaskan hasil eksperimen yang diperoleh secara lisan maupun tertulis, membuat contoh penerapan dalam kehidupan sehari-hari, menuliskan hasil diskusi dan memuat evaluasi tentang pemahaman peserta didik baik secara lisan maupun tertulis (Nana et al., 2014; 2016).

Model pembelajaran POE2WE dapat menjadikan peserta didik sebagai subjek di dalam pembelajaran. peserta didik secara aktif menemukan suatu konsep melalui pengamatan atau eksperimen secara langsung, bukan dari menghafal buku materi maupun penjelasan dari guru. Model ini memungkinkan peserta didik aktif dalam proses pembelajaran, memberikan kesempatan kepada peserta didik untuk konstruktivistik pengetahuannya, mengkomunikasikan pemikirannya dan menuliskan hasil diskusinya sehingga peserta didik lebih menguasai dan memahami konsep yang akan berdampak pada peningkatan prestasi belajar peserta didik Model ini memberikan kesempatan kepada peserta didik untuk melakukan konstruksi pengetahuan yang dimilikinya, melakukan 
pengamatan terhadap fenomena serta mengkomunikasikan gagasan yang dia perolah dari proses diskusi sehingga peserta didik akan lebih mudah menguasai konsep yang diajarkan (Nana, 2014, 2016; Nana et al., 2014; Nana dan Surahman, 2019, 2020; Permatasari, 2011; Rahayu et al., 2013; Samosir, 2010).

Penggabungan tahapan-tahapan pembelajaran model POEW dan model pembelajaran Fisika dengan Pendekatan Konstruktivistik maka dapat di susun langkah-langkah pembelajaran model POE2WE secara terinci sebagai berikut (Nana dan Surahman, 2019; 2020):

\section{a) Prediction}

Tahap prediction yaitu peserta didik membuat prediksi atau dugaan awal terhadap suatu permasalahan. Permasalahan yang ditemukan berasal dari pertanyaan dan gambar tentang materi yang disampaikan oleh guru yang ada di Lembar Kerja peserta didik (LKS)/buku peserta didik sebelum peserta didik membuat prediksi. Pembuatan prediksi jawaban tahap Prediction pada model POEW identik dengan fase Engagenent pada pendekatan konstruktivistik. Guru mengajukan pertanyaan yang dapat mendorong peserta didik untuk dapat membuat prediksi atau jawaban sementara dari suatu permasalahan.

b) Observation

Tahap Observation yaitu untuk membuktikan prediksi yang telah di buat oleh peserta didik. Peserta didik diajak melakukan eksperimen berkaitan dengan masalah atau persoalan yang di temukan. Selanjutnya peserta didik mengamati apa yang terjadi, kemudian peserta didik menguji kebenaran dari dugaan sementara yang telah dibuat. Tahap Observation pada model POEW identik dengan fase Exploration pada pendekatan konstruktivistik.

c) Explanation

Tahap Explanation atau menjelaskan yaitu peserta didik memberikan penjelasan terhadap hasil eksperimen yang telah dilakukan. Penjelasan dari peserta didik dilakukan melalui diskusi dengan anggota kelompok kemudian tiap kelompok mempresentasikan hasil diskusinya di depan kelas. Jika prediksi yang di buat peserta didik ternyata terjadi di dalam eksperimen, maka guru membimbing peserta didik merangkum dan memberi penjelasan untuk menguatkan hasil eksperimen yang dilakukan. Namun jika prediksi peserta didik tidak terjadi dalam eksperimen, maka guru membantu peserta didik mencari penjelasan mengapa prediksi atau dugaannya tidak benar. Tahap explanation identik dengan fase explanation pada pendekatan konstuktivistik.

d) Elaboration

Tahap elaboration yaitu peserta didik membuat contoh atau menerapkan konsep dalam kehidupan sehari-hari. Tahap elaboration di ambil dari pendekatan konstruktivistik. Tahap ini guru mendorong peserta didik untuk menerapkan konsep baru dalam situasi baru sehingga peserta didik lebih memahami konsep yang di ajarkan guru. Tahap ini pengembangan dari pendekatan konstruktivistik.

e) Write

Tahap write atau menulis yaitu melakukan komunikasi secara tertulis, merefleksikan pengetahuan dan gagasan yang dimiliki peserta didik Menurut Masingilia dan Wisniowska (1996) dalam (Yamin \& Ansari, 2012) menulis dapat membantu peserta didik untuk mengekspresikan pengetahuan dan gagasan mereka. peserta didik menuliskan hasil diskusi dan menjawab pertanyaan yang ada pada LKS. Selain itu pada tahap write ini, peserta didik membuat kesimpulan dan laporan dari hasil eksperimen. Tahap ini merupakan pengembangan dari model TTW.

f) Evaluation

Tahap Evaluation yaitu evaluasi terhadap pengetahuan, keterampilan dan perubahan proses berpikir peserta didik. Pada tahap ini peserta didik di evaluasi tentang materi gerak lurus berupa lisan maupun tulisan. Tahap ini merupakan pengembangan dari pendekatan konstruktivistik. 
Tabel 1. Sintaks Pengembangan model POE2WE

\begin{tabular}{|c|c|c|c|}
\hline No. & $\begin{array}{l}\text { Sintaks POEW } \\
\text { (Samosir, 2010) }\end{array}$ & $\begin{array}{c}\text { Sintaks Model } \\
\text { Pembelajaran dengan } \\
\text { Pendekatan } \\
\text { Kontruktivistik (Duffy } \\
\text { dan Junassen, 1992) }\end{array}$ & $\begin{array}{l}\text { Model POE2WE (Nana et al., } \\
\text { 2014) }\end{array}$ \\
\hline 1. & $\begin{array}{l}\text { (Prediction) } \\
\text { membuat prediksi, } \\
\text { membuat dugaan. }\end{array}$ & $\begin{array}{l}\text { (Engagement) } \\
\text { pendahuluan } \\
\text { membuat pertanyaan } \\
\text { menggali pengetahuan } \\
\text { awal peserta didik. }\end{array}$ & $\begin{array}{l}\text { (Prediction) } \\
\text { Membuat dugaan atau prediksi. } \\
\text { Tahap Engagement identik } \\
\text { dengan Predict pada POEW }\end{array}$ \\
\hline 2. & $\begin{array}{l}\text { (Observation) } \\
\text { Melakukan } \\
\text { penelitian, } \\
\text { pengamatan }\end{array}$ & $\begin{array}{l}\text { (Exploration) menguji } \\
\text { prediksi ,melakukan dan } \\
\text { mencatat hasil } \\
\text { pengamatan. }\end{array}$ & $\begin{array}{l}\text { (Observation) Melakukan } \\
\text { observasi/pengamatan Tahap } \\
\text { Exploration identik dengan tahap } \\
\text { observation pada POEW. }\end{array}$ \\
\hline 3. & $\begin{array}{l}\text { (Explanation) Yaitu } \\
\text { memberi penjelasan }\end{array}$ & $\begin{array}{l}\text { (Explation) menjelaskan } \\
\text { konsep dengan kalimat } \\
\text { mereka sendiri }\end{array}$ & $\begin{array}{l}\text { (Explanation) Menjelaskan Pada } \\
\text { tahap explanation identik dengan } \\
\text { explanation pada pendekatan } \\
\text { konstruktivistik }\end{array}$ \\
\hline 4. & $\begin{array}{l}\text { (Write) Membuat } \\
\text { kesimpulan }\end{array}$ & $\begin{array}{l}\text { (Elaboration) Aplikasi } \\
\text { konsep dalam kehidupan } \\
\text { sehari-hari. }\end{array}$ & $\begin{array}{l}\text { (Elaboration) Aplikasi konsep } \\
\text { dalam kehidupan sehari-hari } \\
\text { merupakan pengembangan dari } \\
\text { pendekatan Konstruktivistik }\end{array}$ \\
\hline 5. & & $\begin{array}{l}\text { (Evaluation) Evaluasi } \\
\text { terhadap pengetahuan, } \\
\text { keterampilan dan } \\
\text { perubahan proses berpikir } \\
\text { peserta didik. }\end{array}$ & $\begin{array}{l}\text { (Write) Menuliskan hasil diskusi } \\
\text { sebagai kesimpulan. Merupakan } \\
\text { pengembangan dari model POEW }\end{array}$ \\
\hline 6. & & & $\begin{array}{l}\text { (Evaluation) Evaluasi terhadap } \\
\text { efektivitas fase-fase sebelumnya. } \\
\text { Merupakan pengembangan dari } \\
\text { pendekatan Konstruktivistik }\end{array}$ \\
\hline
\end{tabular}

Sumber: $\quad$ Nana, Surahman E. 2019. Pengembangan Inovasi Pembelajaran Digital Menggunakan Model Blended POE2WE di Era Revolusi Industri 4.0. Prosiding SNFA (Seminar Nasional dan Aplikasinya), 82-90.

Tabel 2. Kegiatan Model Pembelajaran Model POE2WE

\begin{tabular}{|c|c|c|}
\hline Fase-fase & Kegiatan Guru & Kegiatan Peserta \\
\hline Prediction & $\begin{array}{lll}\text { - } & \text { Menyampaikan } \\
\text { pembelajaran. } & \text { tujuan } \\
\text { - } & \text { Mengajukan pertanyaan kepada } \\
& \text { siswa } \\
\text { - } & \text { Menginventarisi prediksi dan alasan } \\
& \text { yang di kemukakan peserta didik } \\
\end{array}$ & $\begin{array}{llr}\text { - } & \text { Memperhatikan penjelasan dari } \\
\text { - } & \text { guru. } & \text { Memprediksi } \\
& \text { pertanyaan dari guru } & \\
\text { - } & \begin{array}{l}\text { Mendiskusikan } \\
\text { prediksinya }\end{array} \\
\end{array}$ \\
\hline Observation & $\begin{array}{ll}\text { - } & \text { Mendorong peserta didik untuk } \\
\text { bekerja secara kelompok } \\
\text { - } & \text { Membagikan LKS } \\
\text { - } & \text { Mengawasi kegiatan percobaan } \\
& \text { yang dilakukan oleh peserta didik }\end{array}$ & $\begin{array}{ll}\text { - } & \text { Membentuk kelompok } \\
\text { - } & \text { Melakukan percobaan } \\
\text { - } & \text { Mengumpulkan data hasil } \\
\text { - } & \text { percobaan } \\
\text { - } & \text { Melakukan diskusi kelompok } \\
\end{array}$ \\
\hline Explanation & $\begin{array}{l}\text { - Mendorong peserta didik untuk } \\
\text { menjelaskan hasil percobaan. }\end{array}$ & $\begin{array}{l}\text { - } \begin{array}{l}\text { Mengemukakan pendapatnya } \\
\text { tentang hasil percobaan }\end{array}\end{array}$ \\
\hline
\end{tabular}




\begin{tabular}{|c|c|c|}
\hline & 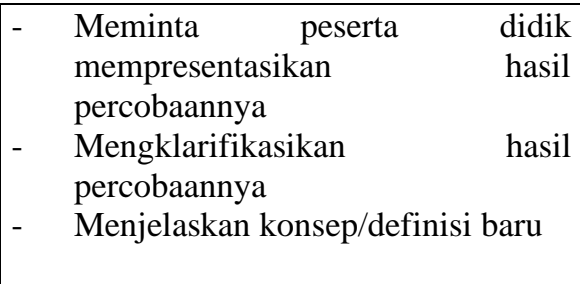 & 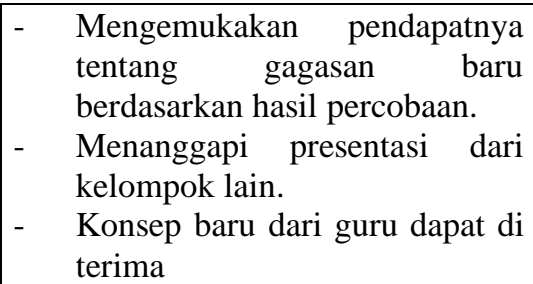 \\
\hline Elaboration & 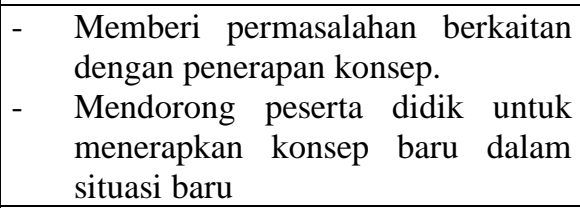 & 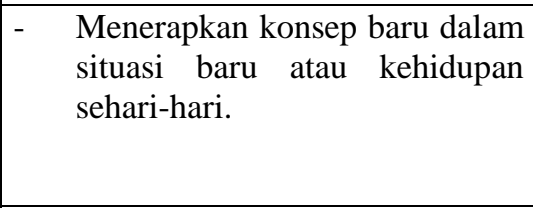 \\
\hline Write & $\begin{array}{l}\text { - Memberi kesempatan kepada } \\
\text { peserta didik untuk mencatat hasil } \\
\text { diskusi serta kesimpulan. }\end{array}$ & $\begin{array}{ll}\text { - } & \text { Mencatat hasil penjelasan dan } \\
\text { kesimpulan dari guru dan } \\
\text { diskusi kelompok }\end{array}$ \\
\hline Evaluation & 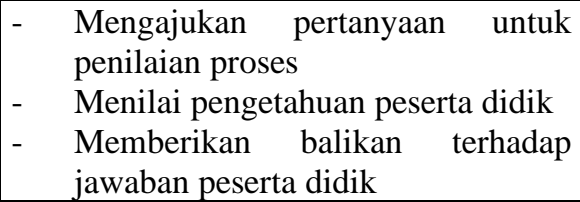 & $\begin{array}{ll}\text { - } & \text { Menjawab pertanyaan } \\
\text { berdasarkan data } \\
\text { - } \quad \text { Mendemonstrasikan } \\
\text { kemampuan dalam penguasaan } \\
\text { konsep }\end{array}$ \\
\hline
\end{tabular}

Sumber: $\quad$ Nana, Surahman E. 2019. Pengembangan Inovasi Pembelajaran Digital Menggunakan Model Blended POE2WE di Era Revolusi Industri 4.0. Prosiding SNFA (Seminar Nasional dan Aplikasinya), 82-90.

\subsection{Blog}

Pada awalnya, kata blog dipakai sebagai kependekan web log, yaitu istilah yang pertama kali digunakan oleh Jorn Barger pada bulan Desember 1997. Jorn Barger menggunakan istilah web log untuk menyebut kelompok website pribadi yang selalu update secara kontinu dan berisi link ke website lain yang mereka anggap menarik disertai dengan komentar-komentar mereka sendiri (Santoso, 2009: 132).

Istilah blog memiliki definisi yang berbeda-beda dari setiap penelitinya dikarenakan perbedaan definisi secara struktural. Selain itu, blog diartikan sebagai komunikasi internet yang digunakan untuk memberi informasi lewat media sosial (Boyd, 2006: 5). Blog berisi fitur-fitur berupa informasi yang berbasis teknologi baik motivasi yang dideskripsikan. Penggunaan blog pada intinya berkaitan dengan pengetahuan yang menjadikan penggunanya untuk menganalisis berbagai informasi yang berbeda-beda dari pemblog. Di sisi lain, pembuat informasi lewat blog yaitu blogger dengan tujuan untuk memberi informasi bagi pengguna blog. Blog juga dianggap sebagai komunitas yang mengikat blogger-blogger lain untuk berkarya dalam media internet (Silva, 2016: 83; Nana, 2018: 192)

\subsection{Wordpress}

Wordpress.com adalah salah satu di antara sekian banyak layanan blog yang cukup populer. Banyak blogger yang menggunakan wordpress sebagai pilihan layanan blog yang mereka gunakan, baik secara keseluruhan maupun sebagian("engine” nya saja). Wordpress biasa digunakan oleh blogger yang memang sangat menginginkan kepopuleran. Hal ini karena layanan blog wordpress ramah komentar. Artinya pembaca bisa menyampaikan komentar mereka dengan sangat mudah pada kotak komentar yang selalu tersedia di bawah setiap artikel. (Santoso, 2009: 133).

Wordpress tidak hanya sebagai blog tool yang dapat diinstal ke server Anda sendiri namun juga menyediakan layanan hosting blog gratis sebagai layanan blogger (Budiarto, 2010:18). Jadi Anda memiliki dua opsi yakni menggunakan Wordpress untuk hosting blog sendiri maupun menumpang blog gratis pada www.wordpress.com. Wordpress.com merupakan situs layanan blog 
yang menggunakan mesin Wordpress, didirikan oleh perusahaan Automattic. Dengan mendaftar pada situs Wordpress.com, pengguna tidak perlu melakukan instalasi atau konfigurasi yang cukup sulit. (Anjarkususma dan Soepeno, 2014: 65).

\subsection{Inovasi Pembelajaran}

Sebelum membahas inovasi pembelajaran, terlebih dahulu perlu diketahui konsep dari inovasi itu sendiri. Inovasi berkaitan dengan pembaharuan di bidang teknologi. Secara harfiah, inovasi berarti penyesuaian, perbaikan, pengembangan, proyek, percobaan, reformasi atau pembaharuan. Inovasi terletak pada rencana, metode, proses, teknologi, dan bagaimana cara implementasinya melalui transformasi (Walder, 2014: 196). Selain itu, inovasi menyangkut pada sebuah ide, gagasan, praktik yang diterima dalam masyarakat sebagai suatu yang baru dan mutakhir. Berkaitan dengan inovasi, pendidikan juga memerlukan pembaharuan untuk menyesuaikan perkembangan zaman sesuai kebutuhan yang disebut dengan inovasi pembelajaran (Nana, 2018: 192-193)

Inovasi pembelajaran sebagai perubahan yang baru dalam meningkatkan kemampuan demi mencapai tujuan tertentu berupa praktik-praktik pendidikan. Tujuan tersebut berkaitan dengan usaha untuk memecahkan persoalan dalam pendidikan dan memperbaiki sistem pendidikan yang kurang sesuai dengan implementasinya (Shalikhah, 2017: 13). Selanjutnya inovasi pembelajaran sebagai suatu ide, gagasan, atau tindakan-tindakan di bidang kurikulum maupun pengajaran yang dianggap mengalami pembaharuan untuk memecahkan dan memberikan solusi terhadap permasalahan dalam pendidikan (Sanjaya, 2010: 317-318; Nana, 2018: 192-193).

\subsection{Penerapan Model POE2WE Berbasis Blog Wordpress sebagai Inovasi Pembelajaran Digital di Sekolah Menengah Atas}

Salah satu masalah dalam proses pengajaran di sekolah yaitu bagaimana mengembangkan keterampilan siswa agar menjadi kreatif dan sesuai dengan bakatnya. Setiap siswa dilatih sesuai dengan keterampilan dan bakat yang dimiliki agar dapat meningkatkan motivasi. Keterampilan yang harus dimiliki oleh siswa berkaitan dengan penalaran verbal-numerik, pemikiran secara abstrak, mengingat informasi sesuai dengan keabsahan data (Cetinkaya, 2014: 3722-3723). Pengembangan keterampilan siswa dapat melalui berbagai inovasi dalam pembelajaran yaitu dengan menggunakan model yang tepat dan sesuai dengan karakteristik siswa (Nana, 2018: 193)

Model POE2WE adalah salah satu solusi kreatif dengan pendekatan konstruktivis yang dianggap memiliki efek pada kreativitas siswa di masa depan. Beberapa peneliti meyakini bahwa kreativitas berupa masalah yang akan dipecahkan, sejumlah ide yang relevan, proses memberikan solusi dari divergen ke konvergen (Lin, 2017: 2-3). Sebagaimana penjelasan sebelumnya bahwa masalah dapat dipecahkan dengan mengidentifikasi dan menyeleksi masalah sesuai dengan kreatif (Wimmer, 2016: 2-3). Proses mengidentifikasi dengan model POE2WE secara kreatif maka diperlukan pembaharuan yang berbasis teknologi dengan blog. Blog yang mudah untuk digunakan berisi informasi secara Online yang dapat mengembangkan wawasan siswa dalam belajar agar termotivasi (Pifarre et al, 2014: 74; Nana, 2018: 193). Wordpress.com adalah salah satu dari banyak layanan blog yang populer. Banyak blogger menggunakan wordpress sebagai pilihan layanan blog mereka, secara keseluruhan atau sebagian (hanya "engine"). Wordpress tidak hanya sebagai blog tool yang dapat diinstal ke server Anda sendiri namun juga menyediakan layanan hosting blog gratis sebagai layanan blogger (Budiarto, 2010:18). Jadi Anda memiliki dua opsi yakni menggunakan Wordpress untuk hosting blog sendiri maupun menumpang blog gratis pada www.wordpress.com. Wordpress.com merupakan situs layanan blog yang menggunakan mesin Wordpress, didirikan oleh perusahaan Automattic. Dengan mendaftar pada situs Wordpress.com, pengguna tidak perlu melakukan instalasi atau konfigurasi yang cukup sulit. (Anjarkususma dan Soepeno, 2014: 65). 
Pada dasarnya, inovasi dalam pembelajaran yang menunjang kreativitas baik secara implisit dan eksplisit tetap menjelaskan pentingnya mengetahui berbagai informasi baik dari sumber media cetak maupun media elektronik yaitu internet (Ohman, 2011: 381). Adanya berbagai alasan yang membuat keyakinan dan pandangan guru sebagai pengajar dalam menerapkan model pembelajaran disesuaikan dengan kebutuhan dan tujuan yang dicapai. Di lain pihak, penggunaan inovasi dalam pembelajaran yaitu dengan blog terkadang membutuhkan kekhususan pengajar agar dapat menyampaikan informasi secara interaktif (Errington, 2007: 41; Nana, 2018: 193).

\section{PENUTUP}

Dari berbagai pembahasan yang telah diuraikan, kesimpulan dapat ditarik dan ditafsirkan bahwa model pembelajaran POE2WE secara kreatif dapat meningkatkan motivasi siswa untuk lebih termotivasi dalam keberhasilan pembelajarannya. Kecukupan keterampilan, kepintaran atau tingkat intelektual dan bakat siswa dapat mempengaruhi hasil yang diperoleh, sehingga perlu profesionalisme guru sebagai instruktur untuk mengarahkan siswa agar lebih kreatif dengan media internet yang merupakan penggunaan Blog Wordpress.

\section{UCAPAN TERIMA KASIH}

Terima kasih kepada bapak Dr. Nana M.Pd. selaku dosen pengampu Fisika Sekolah 2 dan semuanya yang telah membantu demi kesempurnaan artikel ini menjadi lebih baik.

\section{DAFTAR PUSTAKA}

Anjarkusuma D., Soepeno B. (2014). Penggunaan Aplikasi CMS Wordpress untuk Merancang Website Sebagai Media Promosi pada Maroon Wedding Malang. Jurnal Akuntasi, Ekonomi dan Manajemen Bisnis. 2 (1) 63-69

Boyd, Danah. (2006). A blogger's blog: exploring the definition of a medium. Reconstruction, 6 (4), 1-21. http://reconstruction.eserver.org/064/boyd.html.

Budiarto, Raden. 2010. Wordpress, Not just A blog!. Yogyakarta: Andi

Cetinkaya, C. (2014). The effect of gifted students creative problem solving program on creative thinking. Social and Behavioral Sciences, 116, 3722-3723. Doi: 10.1016/j.sbspro.2014.01.830

Duffy, T. M., \& Jonassen, D. H. (1992). Constructivism and the technology of instruction: A conversation. Hillsdale, New Jersey Hove, London: Lawrence Earlbaum Associates.

Errington, E. (2004) The impact of teacher beliefs on flexible learning innovation: some practices and possibilities for academic developers. Innovations in Education and Teaching International, 41 (1), 39-47. Doi. 10.1080/1470329032000172702.

Findikoglu, F., \& Ilhan, D. (2016). Realization of a Desired Future: Innovation in Education. Universal Journal of Educational Research, 4(11), 2574-2580. Doi. 10.13189/ujer.2016.041110.

Lee, Y. J. (2011). A study on the effect of teaching innovation on learning effectiveness with learning satisfaction as a mediator. World Transactions on Engineering and Technology Education, 9 (2), 92-101.

Lin, C. Y. (2017). Threshold effects of creative problem-solving attributes on creativity in the math abilities of taiwanese upper elementary students. https://doi.org/10.1155/2017/4571383.

Nana dan Surahman E. (2020). POE2WE Model as an Alternative for Learning Physics in Industrial Revolution 4.0 Era. Advances in Social Science, Education and Humanities Research, 397(2), 1013-1022 
Nana, Dewi R., \& Muhammad, A., Sajidan (2016) The Effectiveness of Scientific Approach Through Predict, Observe, Explain, Elaborate, Write and Evaluation (POE2WE) Model on the Topic of Kinetics (Rectilinear Motion) at Senior High School. The Social Sciences, 11(6), 1028-1034.

Nana, Sajidan, Akhyar, M., \& Rochsatiningsih, D. (2014). The development of Predict, Observe, Explain, Elaborate, Write, and Evaluate (POE2WE) Learning Model in Physics Learning at Senior Secondary School. Journal of Education and Practice, 5(19), 56-65.

Nana, Surahman E. (2019). Pengembangan Inovasi Pembelajaran Digital Menggunakan Model Blended POE2WE di Era Revolusi Industri 4.0. Prosiding SNFA (Seminar Nasional dan Aplikasinya), 82-90.

Nana. (2014). Pengembangan model POE2WE dalam pembelajaran Fisika SMA. Universitas Sebelas Maret.

Nana. (2018). Penerapan Model Creative Problem Solving Berbasis Blog sebagai Inovasi Pembelajaran di Sekolah Menengah Atas dalam Pembelajaran Fisika. Prosiding SNFA (Seminar Nasional Fisika dan Aplikasinya). 190-195

Nurdyansyah, Widodo A. (2015). Inovasi Teknologi Pembelajaran. Sidoarjo: Nizamia Learning Center.

Pifarre, M., Guijosa, A., \& Argelagos, E. (2014). Using a blog to create and support a community of inquiry in secondary education. E-Learning and Digital Media, 11 (1), 72-87. http://dx.doi.org/10.2304/elea.2014.11.1.72

Rahayu, S., Widodo, A. T., \& Sudirman. (2013). Pengembangan perangkat pembelajaran model POE berbantuan media "I am Scientist”. Innovatif: Journal of Curriculum and Education Technology, 2(1), 128-133.

Samosir, H. (2010). Model Pembelajaran Predict-Observe-Explain-Write (POEW) untuk meningkatkan penguasaan konsep kalor dan keterampilan berpikir kritis siswa SMA. Universitas Pendidikan Indonesia.

Sandberg, K.W., \& Ohman, G. (2011). Learning in innovation development. Social and Behavioral Sciences, 28 , $379-383$.

Sanjaya, W. (2010). Kurikulum dan pembelajaran: Teori dan praktik Pengembangan Kurikulum Tingkat Satuan Pendidikan (KTSP). Jakarta : Kencana

Santoso D. B. (2009). Pemanfaatan Teknologi Search Engine Optimazion sebagai Media untuk Meningkatkan Popularitas Blog Wordpress. Jurnal Teknologi Informasi DINAMIK, 14(2), 131-136.

Serdyukov, P. (2017). Innovation in education: what works, what doesn't, and what to do about it? Journal of Research in Innovative Teaching \& Learning, 10 (1), 4-33. https://doi.org/10.1108/JRIT-10-2016-0007

Shalikhah, N. D., Primadewi, A., \& Iman, M. S. (2017). Media pembelajaran interaktif lectora inspire sebagai inovasi pembelajaran. WARTA LPM, 20 (1), 9-16

Silva, E. C. (2016). Understanding meaning and control in political blogs. New Media \& Society, 18 (1), 82-98. DOI: $10.1177 / 1461444814538633$

Walder, A. M. (2014). The concept of pedagogical innovation in higher education. Education Journal, 3 (3), 195-202. Doi: 10.11648/j.edu.20140303.22. 
Wimmer, L. (2016). Problem solving as a sufficient condition of the creative process: a case for closer cooperation of creativity research and problem solving research. Doi: 10.3389/fpsyg.2016.00488.

Yamin, M., \& Ansari, B. I. (2012). Taktik mengembangkan kemampuan individual siswa. Jakarta: Gaung Persada Press. 